Document downloaded from:

http://hdl.handle.net/10251/121347

This paper must be cited as:

Meseguer Dueñas, JM.; Vidaurre, A.; Molina Mateo, J.; Riera Guasp, J.; Martínez Sala, RM. (2018). Validation of Student Peer Assessment of Effective Oral Communication in Engineering Degrees. IEEE-RITA: Latin-American Learning Technologies Journal. 13(1):1116. https://doi.org/10.1109/RITA.2018.2801897

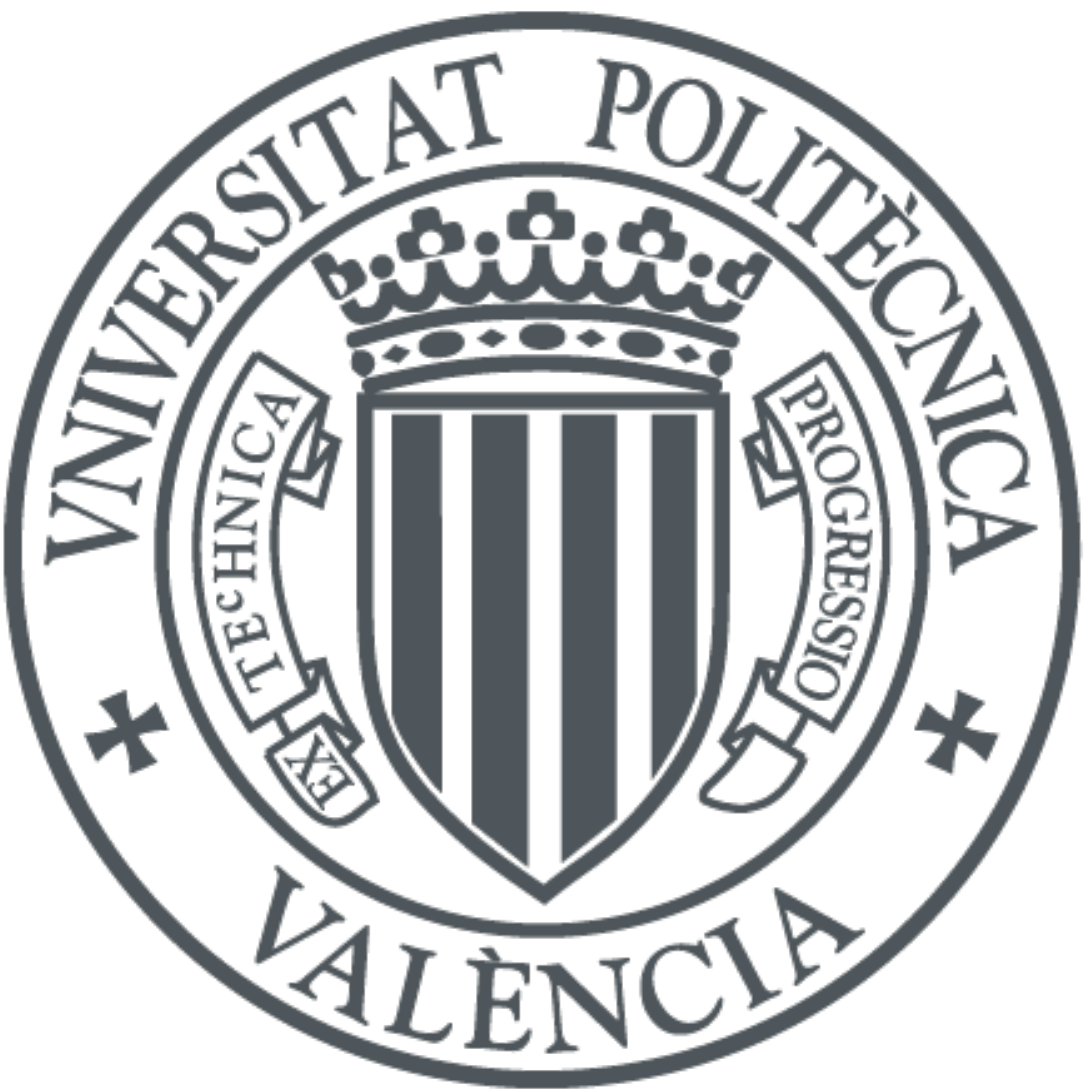

The final publication is available at

http://doi.org/10.1109/RITA.2018.2801897

Copyright Institute of Electrical and Electronics Engineers

Additional Information 


\title{
Validation of student peer assessment of effective oral communication in engineering degrees
}

\author{
José M. Meseguer-Dueñas, ${ }^{a}$ Ana Vidaurre, ${ }^{\mathrm{b}}$ José Molina-Mateo, ${ }^{\mathrm{c}}$ Jaime Riera, ${ }^{\mathrm{d}}$ Rosa Martínez Sala ${ }^{\mathrm{e}}$
}

\begin{abstract}
Peer assessment is a form of collaborative learning in which students evaluate learning products prepared by other students. We present the results of an analysis of the assessment of oral presentations by students. A group of students solves a problem, writes a document with the solution, and makes an oral presentation in class to other students. Another group assesses the written document and oral presentation. To help students perform the assessments two rubrics are provided along with other guidance documents that help in writing scientific documents and performing oral presentations. The rubric evaluates five factors of oral communication. The results of the student evaluations are compared with the simultaneous evaluations produced by two lecturers. When making a comparison of the global assessment between lecturers and students we find significant differences. However, when the factor 'use of auxiliary resources' is removed these differences disappear as the factor introduces a difficult to justify dispersion. In addition, the assessment performed by students with and without the help of a rubric is compared and no significant differences are found.
\end{abstract}

Keywords: collaborative learning, teamwork, effective oral communication, peer assessment

\section{INTRODUCTION}

$\mathrm{D}$ eveloping skills in students for cooperating, communi-

cating, and making decisions, among other general skills, is a crucial task in university training. Curricula increasingly specify the way cross-curricular skills are worked and evaluated. Peer evaluation enables students to observe the work of others, ask questions, and conduct a discussion - and this leads to better critical thinking and a better perception of their own work [1], [2], [3], [4]. When work is evaluated by peers in a critical and constructive way, and supported by reasoned comments and interaction among students, an improvement of those who evaluate and those who are evaluated is achieved [5], [6], [7]. Several authors have shown that the quality of work improves when students receive feedback from peers [8], [9], [10], [11]. Weiss [12] suggests that emotions can stimulate attention and stimulate learning.

The opinion of students who are evaluated by their peers is not unanimous, with some negative attitudes, such as doubts about

Departamento de Física Aplicada. Escuela Técnica Superior de Ingeniería del Diseño. Universitat Politècnica de València. España

ajmmesegu@fis.upv.es, bvidaurre@fis.upv.es,_cjmmateo@fis.upv.es, djriera@fis.upv.es, ermsala@ fis.upv.es the abilities of 'peers', or feelings of injustice [13], [14], [15] 16]. Whether positive or negative, peer evaluation always evokes an emotional response [17], [18]. Peer evaluation should be understood as an option for improvement rather than a critique of a work or the person [19]. Lecturers should be able to understand and manage the emotions and minimise possible negative consequences.

Some lecturers are hesitant to use peer evaluation because they have doubts about its validity as they do not trust student scores to match their scores [20], [21]. However, it is necessary to consider that the scores assigned to a product (exam, laboratory report, problem solving task, etc.) can vary from one lecturer to another, as we will later remark in this paper. Even when scores assigned by various lecturers agree, there are many studies that raise doubts about their validity since 'consistent marks' do not necessarily imply 'fair marks' [22], [23].

Falchikov [20] in a study comparing the scores assigned by students with those of lecturers, concludes that when peer evaluation is used it is preferable to do so in a context of evaluating academic products in small groups with well understood criteria that are agreed by all, and provide global assessment. Haddad et al. [24] conclude that the differences between student and lecturer evaluation results are reduced when evaluation rubrics are used. According to McGourty et al. [25] maximum attention should be given to the design of peer evaluation to achieve maximum acceptance by lecturers and students (this must be done through a well-structured process that is repeated several times during student training).

Teamwork is one of the strategies used in engineering physics degrees taught at the Higher Technical School of Design Engineering (ETSED) at the Universitat Politècnica de València (UPV). The work of teams, formed by six students, consists of problem solving, experimental work in the laboratory, and writing laboratory reports. In addition to communicating the solution to problems in a written document, one of the members of the team must explain the team solution in class. In other words, effective communication, both written and spoken, is being developed. Evaluation of problem-solving products in written documents and oral presentations are evaluated by another peer team. The students receive information on how to make the evaluation and receive a series of guidance documents that include an evaluation rubric.

DOI (Digital Object Identifier) Pendiente 
Resources that facilitate and automate peer evaluation are now available. The use of 'clickers' seems to be superseded by the widespread use of smartphones, tablets, or laptops in the classroom. By using these devices, students can evaluate presentations through participation systems in the classroom with applications such as Socrative or Kahoot [26].

Training in teamwork, effective communication, and evaluation skills are especially important in the professional activities of future engineers [27], [28]. At the UPV, it is planned that these skills, and others, will be introduced from the first year of training for engineers, and that these skills will be evaluated at three levels of competence (two levels in the degree course and one in the masters course).

In previous work we analysed the peer evaluation of written documents [29], [30]. It is shown that with the proposed methodology there are no significant differences between the assessments made by expert lecturers and student teams. The present paper analyses the results of peer evaluations of oral presentations, comparing them with those performed by two expert evaluators (course lecturers). The presentations were carried out during the 2015-2016 academic year in a group of 100 physics students (during courses on physics and electricity) in the first year of a degree course in industrial electronic and automatic engineering at the UPV. Partial results of this work are shown in an article published in INRED2016 [28]. The e-learning platform at the UPV is used - which enables sharing and saving documents, maintaining authorship, control of plagiarism, and the possibility of completing exams and online surveys. The 'survey' tool enables us to perform part of the peer evaluation of oral presentations in 'real time'.

The hypothesis of this work is that, in an academic context, the results of the team evaluation of oral presentations of the students are not significantly different from those made by expert lecturers.

\section{METHOD}

Students of physics are organised into teams of 5-6 members. To give continuity to the two courses of the subject (physics and electricity), the composition of the work teams remains the same for both courses. Teams must perform six problem-solving tasks in each course.

The organisational chart of the lecturer and student tasks is shown in Figure 1. Various types of tasks are assigned for every lesson. Half of the teams must write a document containing the resolution of a problem proposed by the lecturer. The document should be in accordance with the instructions given in the 'student guide' - which is a set of documents available on the elearning platform with recommendations on effective communication (written and oral), teamwork, and co-evaluation rubrics. ${ }^{1}$ The other half of the teams must evaluate a document prepared by another team by writing a reasoned assessment and following the recommendations of the rubric. Subsequently, one of the problem-solving team members must make the oral presentation of this work to their classmates. The team that has corrected the written document evaluates the corresponding oral presentation. Each team does three effective communication tasks (written and oral) and three evaluation tasks during the course.

Tasks are opened by creating a folder on the e-learning platform (poli[formaT] based on Sakai: https://sakaiproject.org). A series of permissions are given to the students in this folder so they can create, read, and edit their own resources and eliminate documents. A document is uploaded in the folder describing the problem that each team must tackle and which team evaluates. Also included are the deadlines for uploading the problem document and the submission deadline.

Students have documentation with recommendations on how to prepare oral and written communication. They also have a rubric to make the corrections and a guide to evaluate the presentations. All the documentation has a 'student work guide' format [32].

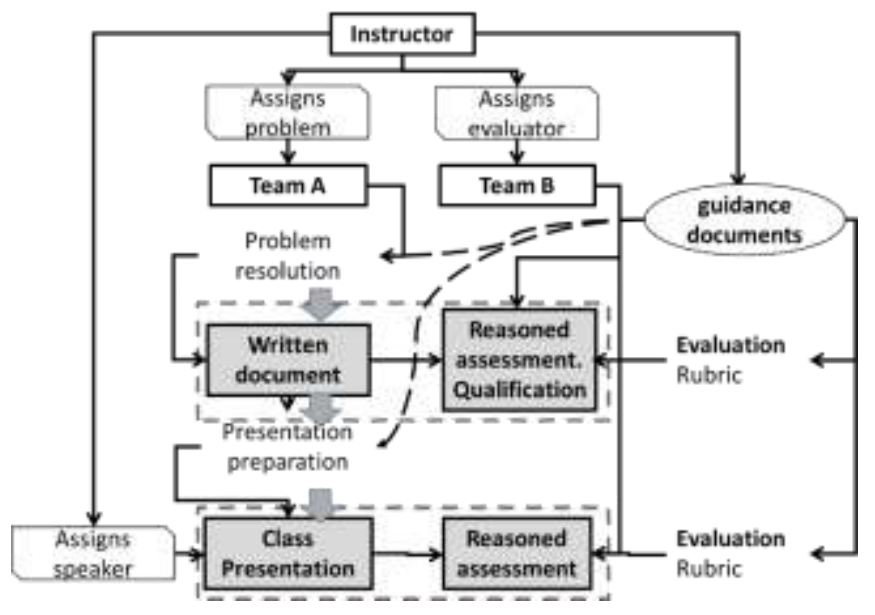

Figure 1: Organisational chart of lecturer and student team work.

Following a rotary order, team members must give an oral presentation of the problem solved in class. Due to coordination between the physics and electricity courses, each students can give an oral presentation.

Once the presentation has been given, the evaluating team, in addition to assessing the presentation with the rubric, will make comments. The two lecturers also evaluate and comment on the presentation.

Five factors are taken into account when evaluating the oral presentations given by each team member: (1) correct and professional language; (2) order and clarity; (3) tone of voice and emphasis; (4) use of additional resources; and (5) non-verbal communication. Each of these factors is rated from 1 to 5 on a Likert scale (1 strongly disagree, 2 disagree, 3 neither agree or disagree, 4 agree, and 5 strongly agree). We analyse the evaluations collected for the first 24 presentations of the 2015-2016 academic year. The statistics were analysed using the SPSS v.16 program, establishing a significance level $\alpha$ of 0.05 for all statistical tests. The goal of these studies was to establish the possible existence of significant differences between different groups. Bland-Altman diagrams were used to further analyse 
these differences [33]. These diagrams, which are widely used in medical science, are useful for comparing measurements made with a procedure versus another procedure used as a reference - and show the differences between the two magnitudes when compared to their means. The bias between the two measures (mean of the difference between the two) and the limits of agreement (mean value of the difference \pm twice the standard deviation) are obtained. The differences found in the academic framework can be contextualised using these values.

\section{RESULTS}

\section{A. Expert assessment of oral presentations}

As a previous reference on the assessment variability, we compared the evaluations of 24 oral presentations of the students made by two expert lecturers. These evaluations were made using the same rubric that had been used by the students and with the same Likert scale. The average values of the five factors in the rubric was given on a scale of 0 to 10 points (from now on all Likert scale values will be $0,2.5,5,7.5$ and 10). As a first step, the existence or non-existence of significant differences between lecturer averages is considered. To answer this question, a t-Student test is performed, proposing as a null hypothesis the existence of no significant differences. The results of the test (see Table 1) confirm the hypothesis, but are not conclusive $(\mathrm{p}=0.053)$, and so we performed a more detailed study on data dispersion.

TABLE 1: RESULT OF T-STUDENT TEST ON THE AVERAGE OF THE TWO EXPERTS EVALUATIONS

\begin{tabular}{|l|l|}
\hline Lecturers & Average \\
\hline Expert 1 $\bar{x}(\mathrm{DE})$ & $7.8(1.1)$ \\
\hline Expert $2 \bar{x}(\mathrm{DE})$ & $7.2(1.1)$ \\
\hline $\mathrm{T}$ & 1.98 \\
\hline Statistical significance & $\mathrm{p}=0.053$ \\
\hline
\end{tabular}

These results are shown in the Bland-Altman diagram shown in Figure 2. The average value of the two lecturer assessments (horizontal axis) versus the difference (vertical axis) is represented for every presentation. As a result, a bias of 0.7 points of one lecturer (expert 1) over the other (expert 2) can be observed, being 1.9 the interval amplitude of the limits of agreement.

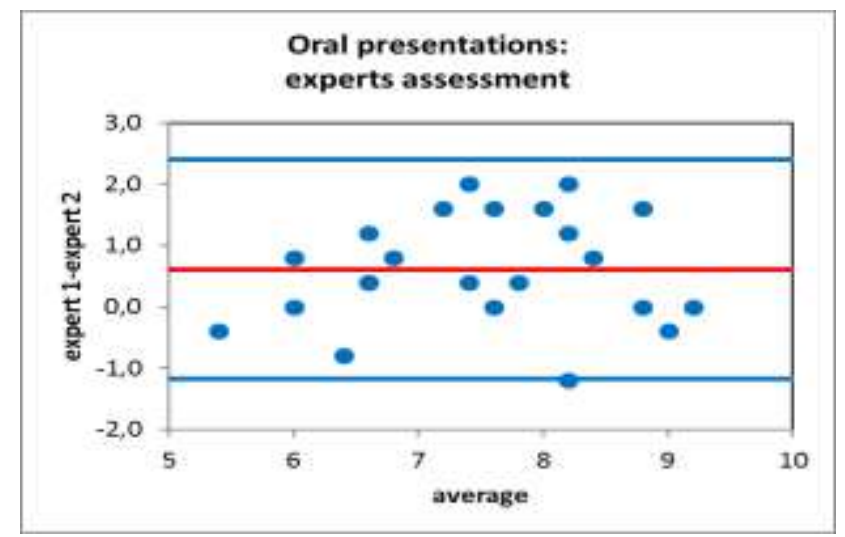

Figure 2: Comparison of the assessment of two expert lecturers of the oral presentations
Both the bias and limits of agreement are less than one unit on the scale used and both can be considered as reasonable. To compare the values of the evaluation with the evaluation made by the students, the average of the two experts (7.5) will be taken as a reference.

\section{B. Student peer assessment of oral presentations}

The available data corresponds to the evaluation of the 24 oral presentations made by students. Table 2 shows the average value of each factor considered in the evaluations on a scale from 0 to 10. Factor 4, use of additional resources, reaches the highest score (8.4), while factor 3 , which evaluates the tone of voice and emphasis, has the lowest (7.7). Although the difference between the two values is not great, it shows that, even if technological means are mastered, it is necessary for students to work the basic elements of effective oral communication. In any case, the scores can be considered high and the range of variation small.

TABLE 2: STUDENT PEER ASSESSMENT OF THE ORAL PRESENTATIONS

\begin{tabular}{|l|c|c|}
\hline \multicolumn{1}{|c|}{ Factor } & Average & $\begin{array}{c}\text { Standard } \\
\text { deviation }\end{array}$ \\
\hline 1. Language & 8.2 & 1.6 \\
\hline 2. Order and clarity & 8.0 & 1.2 \\
\hline 3. Tone of voice and emphasis & 7.7 & 2.2 \\
\hline 4. Use of additional resources & 8.4 & 1.6 \\
\hline 5. Non-verbal communication & 7.8 & 1.7 \\
\hline Average & 8.0 & 0.3 \\
\hline
\end{tabular}

\section{Comparative analysis: students vs lecturers}

Firstly, we compared the overall result. This result is obtained as the average value of the five analysed factors on the Likert scale from 0 to 10 .

The overall mean value of student assessments is 8.0, which is more than half a point higher than the average of the assessment made by the lecturers (7.5). When performing a t-Student test to assess the differences between both averages, these differences are found to be significant $(p<0.05)$ being $t=2.03$. This difference, although statistically significant, is of the same order as that found between the lecturers $(t=1.98)$.

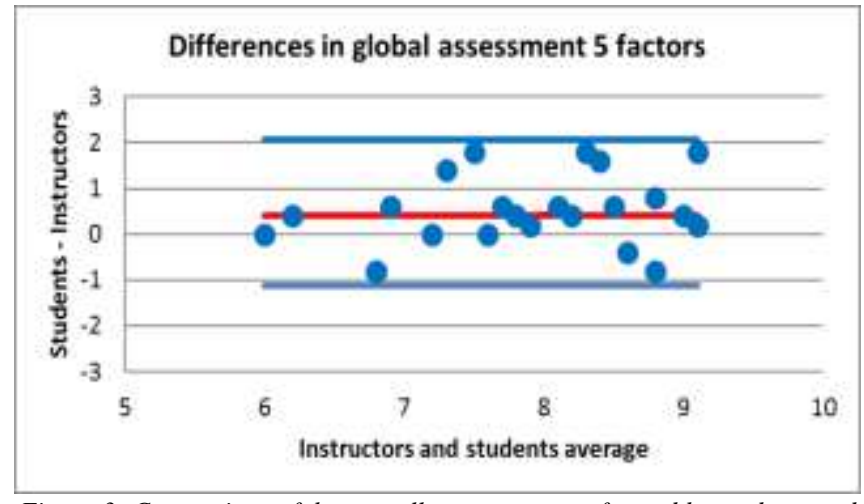

Figure 3: Comparison of the overall assessment performed by students and lecturers. 
The Bland-Altman diagram shown in Figure 3 enables us to analyse in more detail the differences between students and lecturers. When the weighted global assessment of the five factors is analysed, a bias of 0.4 is obtained (the student score is 0.4 points higher than that of the lecturers) and the limits of agreement (the average plus/minus of the two standard deviations) are between -1.3 and 2.1 .

These results show that students and lecturers make similar assessments with a reasonable uncertainty margin (approximately one unit of the Likert scale).

To analyse in more detail the differences between the assessments of students and lecturers, we make a factor-to-factor comparison. The results are shown in Table 3 . From this analysis we infer that no significant differences exist in four of the five factors. Only in factor 4 ('use of additional resources') are significant differences found $(\mathrm{t}=-2.81 ; \mathrm{p}<0.01)$ with the student scores significantly higher than those of lecturers.

TABLE 3: FACTOR TO FACTOR ANALYSIS OF THE ORAL PRESENTATIONS

\begin{tabular}{|lc|c|c|c|c|c|}
\hline \multirow{2}{*}{$\begin{array}{l}\text { Student/ } \\
\text { lecturer }\end{array}$} & \multicolumn{5}{|c|}{ Factors } \\
\cline { 2 - 7 } & 1. & 2. & 3. & 4. & 5. \\
\hline $\begin{array}{l}\text { Students. } \\
\text { (DE) }\end{array}$ & $\bar{x}$ & 8.2 & 8.0 & 7.7 & 8.4 & 7.8 \\
\hline $\begin{array}{l}\text { Lecturer } \\
(1.6)\end{array}$ & $\bar{x}$ & 7.5 & $7.7)$ & $(1.1)$ & $(1.6)$ & $(1.7)$ \\
(DE) & $(1.6)$ & $(1.2)$ & $(2.7)$ & 7.2 & 7.4 \\
\hline $\mathrm{t}$ & $-1.76^{\mathrm{a}}$ & $-0.70^{\mathrm{b}}$ & $0.14^{\mathrm{a}}$ & $-2.81^{\mathrm{a}}$ & $(1.7)$ \\
\hline $\begin{array}{l}\text { Statistical } \\
\text { significance }\end{array}$ & $\mathrm{p}=0.09$ & $\mathrm{p}=0.49$ & $\mathrm{p}=0.89$ & $\mathrm{p}<0.01$ & $\mathrm{p}=0.39$ \\
\hline
\end{tabular}

${ }^{a}$ Equal variances. The parametric method is used to apply t-Student

${ }^{b}$ Not equal variances. The parametric method is not used to apply tStudent

We can make a hypotheses to explain the difference in this factor: one could be that it is the most ambiguous factor and its meaning is not sufficiently clear for students. Another hypothesis may be that the students do not know about the additional resources available for oral presentations. One future action could be to revise the 'student guide' to clarify ambiguities and highlight all the resources involving the use of additional resources (from the blackboard to the most sophisticated multimedia systems).

\section{Analysis of the overall results excluding 'use of additional} resources' factor.

In the first analysis we found that there are clear differences between the student and lecturer assessments when factor 4 of the rubric was considered. For this reason, we perform a second analysis while excluding this factor. Table 4 shows the results obtained by performing a t-Student test in that case. The statistical significance $(p=0.34)$ shows that there are no differences between the averages of the two groups. Therefore, we can state that if we exclude factor 4 there are no significant differences between the student and lecturer assessments.

TABLE 4: ANALYSIS OF THE OVERALL ASSESSMENT OF PRESENTATIONS EXCLUDING THE FACTOR 'USE OF ADDITIONAL RESOURCES'.

\begin{tabular}{|l|l|}
\hline Student/lecturer & Overall average without factor 4 \\
\hline
\end{tabular}

\begin{tabular}{|l|c|}
\hline Students: $\bar{x}(\mathrm{DE})$ & $8.0(1.2)$ \\
\hline Lecturer: $\bar{x}(\mathrm{DE})$ & $7,6(1,0)$ \\
\hline $\mathrm{t}$ & $-0,97^{\mathrm{a}}$ \\
\hline $\begin{array}{l}\text { Statistical } \\
\text { significance }\end{array}$ & $\mathrm{p}=0,34$ \\
\hline
\end{tabular}

${ }^{a}$ Equal variances. The parametric method is used to apply t-Student

Figure 4 shows the Bland-Altman diagram of the differences between students and lecturers of the weighted assessment of all factors excluding the fourth, use of additional resources.

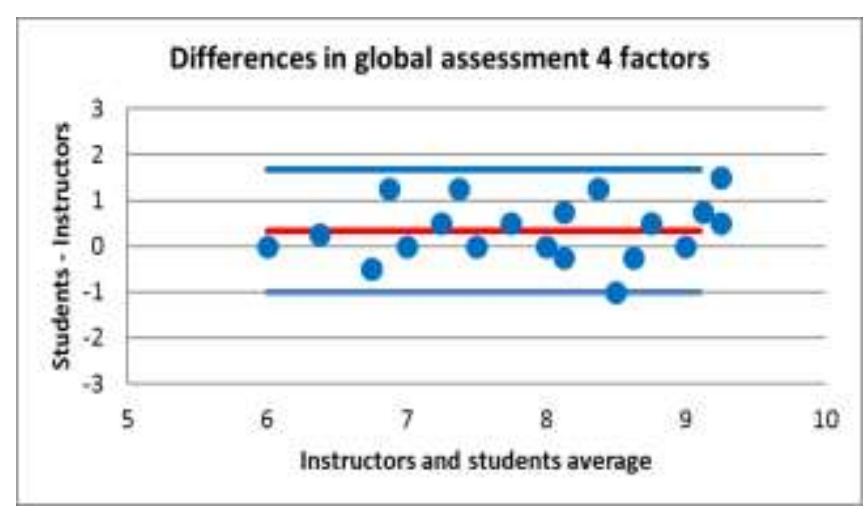

Figure 4: Comparison of the overall assessment of the oral presentations performed by lecturers and students excluding factor 4.

When comparing this diagram with that corresponding to the average values obtained with the five factors (Figure 3), we can clearly see the dispersive effect of factor 4 . We find a bias of 0.4 and limits of agreement $[-1.0 ; 1,8]$. The exclusion of factor 4 causes a reduction in the amplitude of the limits of agreement higher than $20 \%$, changing from \pm 1.7 to \pm 1 .4. Taking into account that the factor 4 introduces dispersion due to an ambiguous definition, it would be justified that we can remove it to interpret the average values.

\section{E. Study of the influence of the rubric}

In order to evaluate the effect of the rubric on the evaluation, some presentations were chosen to be assessed in two ways. One consisting in the peer assessment using the rubric and, at in parallel, students were asked to provide an assessment based on their general impression about the presentation. So we can compare the general evaluation that students do when they use a rubric and when they do not use it. For each of the oral presentations the student evaluations were averaged, without using the rubric, and then compared with that of the group that used the rubric, and found that the difference between them was less than 0.1 .

The t-student test was used as an evaluation tool, proposing as null hypothesis the existence of no significant differences.

The test results (see Table 5) indicate that there were no significant differences between the means of the groups and they were very similar

TABLE 5: ANALYSIS OF THE PRESENTATIONS EVALUATED WITH RÚBRIC OR SURVEY

\begin{tabular}{|l|c|}
\hline Rubric/Survey & Average \\
\hline Rubric: $\bar{x}(\mathrm{DE})$ & $8.1(1,4)$ \\
\hline Survey: $\bar{x}(\mathrm{DE})$ & $8.1(1,1)$ \\
\hline
\end{tabular}




\begin{tabular}{|l|c|}
\hline $\mathrm{t}$ & $0.19^{\mathrm{a}}$ \\
\hline $\begin{array}{l}\text { Statistical } \\
\text { significance }\end{array}$ & $\mathrm{p}=0.851$ \\
\hline
\end{tabular}

${ }^{\text {a }}$ Equal variances. The parametric method is used to apply the t-Student test.

To learn more about the differences between the evaluations, this study was completed with a Bland-Altman analysis. Figure 5 shows a Bland-Altman diagram where the horizontal axis represents the mean of the evaluations (with and without the rubric) and the vertical axis the difference. It is observed that the bias has a value of less than 0.1 as the limit of agreement [-2.4; 2.4].

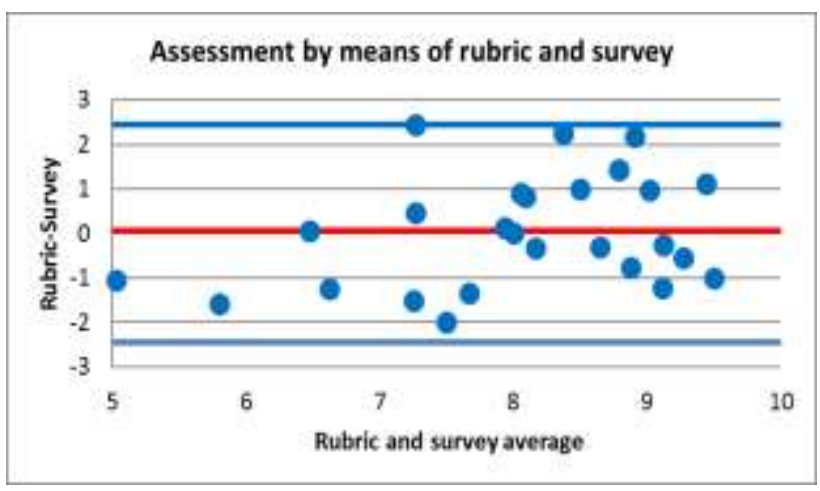

Figure 5: Difference between valuations obtained by rubric and survey.

The bias value shows that very similar results are obtained with both methods. The limits of agreement imply that the variability between both methods may be appreciable.

Although the variability found is acceptable from an academic point of view, it would be interesting to continue working to attain a rubric that facilitates a smaller variability between student evaluations.

\section{CONCLUSIONS}

The results show that in an academic environment the evaluations by students or lecturers of oral presentations do not reveal significant differences. This result indicates that students perform a thorough assessment, use the guide and assessment rubric, and follow recommendations from lecturers. The same result was obtained when students assessed documents written by student peers.

The differences between student and lecturer assessments are of the same order of magnitude as the differences between two lecturers, with a maximum difference of less than one unit of the Likert measurement scale.

The factors used in the assessment rubric (except the factor 'use of additional resources') do not show significant differences between lecturer and student assessments.

Moreover, the overall evaluations carried out by students with and without the rubric are similar. The rubric used by students provides relevant information on specific aspects of oral presentations. The rubric enables an evaluation of objectiveness and further work to reduce variability is desirable.

This work enables the validation of peer evaluation of oral presentations in the studied environment. However, the 'use of additional resources' factor should be better defined to obtain a more precise validation.
Peer assessment performed in work-teams of written documents or oral presentations is revealed as a good opportunity to promote collaborative student learning.

\section{ACKNOWLEDGEMENTS}

Authors would like to thank the ICE in the Universitat Politècnica de València for their help, through the Innovation and Educational Quality Programme and for supporting the team eMACAFI; and support received through the PIME/2014/A025 Project.

\section{REFERENCIAS}

[1] P. Black and D. Wiliam, "Inside the Black Box: Raising Standards Through Classroom Assessment," Phi Delta Kappan, vol. 80, no. 2, pp. $139-148,1998$

[2] L. A. Shepard, "The role of assessment in a learning culture," Educ. Res., pp. 4-14, 2000.

[3] C. L. Lai and G. J. Hwang, "A peer-assessment criteria development approach to improving critical thinking of students," Proc. - 2014 IIAI 3rd Int. Conf. Adv. Appl. Informatics, IIAI-AAI 2014, pp. 355360, 2014.

[4] S. S. J. Lin, E. Z. F. Liu, and S. M. Yuan, "Web-based peer assessment: Feedback for students with various thinking-styles," J. Comput. Assist. Learn., vol. 17, no. 4, pp. 420-432, 2001.

[5] C.-C. Tsai, S. S. . Lin, and S.-M. Yuan, "Developing science activities through a networked peer assessment system," Comput. Educ., vol. 38, no. 1-3, pp. 241-252, 2002.

[6] C. Lundquist, M. A. Skoglund, K. Granström, and T. Glad, "Insights from implementing a system for peer review," IEEE Trans. Educ., vol. 56, no. 3, pp. 261-267, 2013.

[7] N.-F. Liu and D. Carless, "Peer feedback: the learning element of peer assessment," Teach. High. Educ., vol. 11, no. 3, pp. 279-290, 2006.

[8] K.-H. Cheng, H.-T. Hou, and S.-Y. Wu, "Exploring students' emotional responses and participation in an online peer assessment activity: a case study," Interact. Learn. Environ., vol. 22, no. 3, pp. 271-287, 2014

[9] F. J. Prins, D. M. a. Sluijsmans, P. a. Kirschner, and J. Strijbos, "Formative peer assessment in a CSCL environment: a case study," Assess. Eval. High. Educ., vol. 30, no. 4, pp. 417-444, 2005

[10] C. C. Tsai and J. C. Liang, "The development of science activities via on-line peer assessment: The role of scientific epistemological views," Instr. Sci., vol. 37, no. 3, pp. 293-310, 2009.

[11] S.-C. Tseng and C.-C. Tsai, "On-line peer assessment and the role of the peer feedback: A study of high school computer course," Comput. Educ., vol. 49, no. 4, pp. 1161-1174, 2007.

[12] P. R. Weiss, "Emotion and learning," Train. Dev., vol. 54, no. 11, pp. 44-48, 2000.

[13] B. Basnet, L. Brodie, and J. Worden, "Peer assessment of assignment," Proc. - Front. Educ. Conf. FIE, pp. 26-27, 2010.

[14] R. E. Levine, P. A. Kelly, T. Karakoc, and P. Haidet, "Peer evaluation in a clinical clerkship: Students' attitudes, experiences, and correlations with traditional assessments," Acad. Psychiatry, vol. 31, no. 1, pp. 19-24, 2007.

[15] J. H. Kaufman and C. D. Schunn, "Students' perceptions about peer assessment for writing: Their origin and impact on revision work," Instructional Science, vol. 39, no. 3. pp. 387-406, 2011.

[16] M. L. Wen and C.-C. Tsai, "University Students' Perceptions of and Attitudes Toward (Online) Peer Assessment," High. Educ., vol. 51, no. 1, pp. 27-44, 2006.

[17] N. Falchikov, Improving Assessment Through Student Involvement. 2005.

[18] J. Sargeant, K. Mann, D. Sinclair, C. Van Der Vleuten, and J. Metsemakers, "Understanding the influence of emotions and reflection upon multi-source feedback acceptance and use," Adv. Heal. Sci. Educ., vol. 13, no. 3, pp. 275-288, 2008.

[19] A. Casamayor, A. Amandi, and M. Campo, "Intelligent assistance for teachers in collaborative e-learning environments," Comput. Educ., vol. 53, no. 4, pp. 1147-1154, 2009.

[20] N. Falchikov and J. Goldfinch, Student Peer Assessment in Higher Education: A Meta-Analysis Comparing Peer and Teacher Marks, 
vol. 70, no. 3. 2000.

[21] M. S. Ibarra Sáiz, G. Gómez Rodríguez, and M. Á. Gómez Ruiz, "La evaluación entre iguales: beneficios y estrategias para su práctica en la universidad," Rev. Educ. 359, no. March 2016, pp. 206231, 2012.

[22] N. Falchikov and D. Magin, "Detecting Gender Bias in Peer Marking of Students' Group Process Work,” Assess. Eval. High. Educ., vol. 22, no. 4, pp. 385-396, 1997.

[23] G. A. Marcoulides and M. G. Simkin, "Evaluating student papers: The case for peer review.," J. Educ. Bus., vol. 67, no. 2, p. 80, 1991.

[24] R. J. Haddad and Y. Kalaani, "Can undergraduate electrical engineering students assess each other's presentations effectively?," ISEC 2016 - Proc. 6th IEEE Integr. STEM Educ. Conf., pp. 173$180,2016$.

[25] J. Mcgourty, P. Dominick, and R. R. Reilly, "Incorporating Student Peer Review and Feedback into the Assessment Process," 2013 IEEE Front. Educ. Conf., vol. 1, no. November, p. 14-18. IEEE., 1998.

[26] A. I. Wang, "Computers \& Education The wear out effect of a game-based student response system *," Comput. Educ., vol. 82, pp. 217-227, 2015.

[27] A. Mohan, D. Merle, C. Jackson, J. Lannin, and S. S. Nair, "Professional Skills in the Engineering Curriculum," IEEE Trans. Educ., vol. 53, no. 4, pp. 562-571, 2010.

[28] F. Grimaldo-Moreno and M. Arevalillo-Herráez, "Metodología Docente Orientada a la Mejora de la Motivación y Rendimiento Académico Basada en el Desarrollo de Competencias Transversales," IEEE-Rita, vol. 6, no. 2, pp. 70-77, 2011.

[29] A. Vidaurre, M. A. Ramírez, V. Paula, C. Gotor, S. Marín, J. M. Mateo, J. R. Guasp, M. H. G. Valentín, J. Antonio, G. Tejedor, R. M. Sala, and J. M. M. Dueñas, “Avaluació entre companys i treball en equip Introducció,” Conf. Proc. IN-RED 2015, 2015.

[30] R. Martínez-Sala, J. Molina-Mateo, I. Tort-Ausina, and J. M. Meseguer-Dueñas, "Peer review based evaluation in team work: students' assessment," in ICERI2015 Proceedings, 2015, pp. 980-985.

[31] J. M. Meseguer-Dueñas, A. Vidaurre, J. Molina-Mateo, and J. Riera Guasp, "Evaluación entre compañeros de la comunicación oral efectiva,” Conf. Proc. IN-RED 2016, 2016.

[32] "Guia de treball de l'alumne," 2016. [Online]. Available: https://poliformat.upv.es/access/content/user/22449579/guia de treball de 1_alumne/. [Accessed: 11-Jan-2017].

[33] J. M. Bland and D. G. Altman, "Statistical Methods for Assessing Agreement between Two Methods of Clinical Measurement," Lancet, vol. 1, no. 8476, pp. 307-310, Feb. 1986.

José M. Meseguer-Dueñas, Professor at the Department of Applied Physics, Universitat Politècnica de València, Spain. He received his $\mathrm{PhD}$ in industrial engineering from the Universitat Politècnica de València in 1988. His research areas are in the fields of polymer biomaterials and the use of active methodologies and ICTs in university education. He currently manages the Innovation and Educational Quality Team 'Active Methodologies for Learning Physics (eMACAFI)' at the Universitat Politècnica de València.

Ana Vidaurre, Professor at the Department of Applied Physics, Universitat Politècnica de València, Spain. Dr. Vidaurre received a PhD in physical sciences from the Universitat de València in 1990. Her research focuses on polymer bio-materials and the use of active methodologies and ICTs in university education. She is a member of the Innovation and Educational Qualification Team 'Active Methodologies for Learning Physics (e-MACAFI)' of the Universitat Politècnica de València.

José Molina-Mateo, Lecturer at the Department of Applied Physics, Universitat Politècnica de València, Spain. He received his $\mathrm{PhD}$ from the Universitat Politècnica de València in 2003. His research areas are in the fields of polymer material simulation, medical image analysis, and the use of active methodologies and ICTs in university education. He is currently deputy director of the Department of Applied Physics at the Universitat Politècnica de Valencia and responsible for adaptation to the European Higher Education Area.

Jaime Riera, Professor at the Department of Applied Physics, Universitat Politècnica de València, Spain. He received his $\mathrm{PhD}$ in physics from the Universitat de València in 1990. He has directed various projects focused on the transmission of scientific knowledge through information and communication technologies (ICTs). He has produced various documentaries on scientific subjects. He is currently researching at the Multidisciplinary Mathematics Institute in the area of image processing and digital tracking.

Rosa Martínez Sala. Lecturer at the Department of Applied Physics of the Universitat Politècnica de València, Spain. She received a $\mathrm{PhD}$ from the Universitat Politècnica de València in 1995. Her field of research includes the application of non-destructive techniques, such as georadar and infrared thermography, in the analysis of building materials and their pathologies. 